\title{
Synthesis
}

\section{The People Paradox: Self-Esteem Striving, Immortality Ideologies, and Human Response to Climate Change}

\author{
$\underline{\text { Janis L. Dickinson }}^{1}$
}

\begin{abstract}
In 1973, Ernest Becker, a cultural anthropologist cross-trained in philosophy, sociology, and psychiatry, invoked consciousness of self and the inevitability of death as the primary sources of human anxiety and repression. He proposed that the psychological basis of cooperation, competition, and emotional and mental health is a tendency to hold tightly to anxiety-buffering cultural world views or "immortality projects" that serve as the basis for self-esteem and meaning. Although he focused mainly on social and political outcomes like war, torture, and genocide, he was increasingly aware that materialism, denial of nature, and immortality-striving efforts to control, rather than sanctify, the natural world were problems whose severity was increasing. In this paper I review Becker's ideas and suggest ways in which they illuminate human response to global climate change. Because immortality projects range from belief in technology and materialism to reverence for nature or belief in a celestial god, they act both as barriers to and facilitators of sustainable practices. I propose that Becker's cross-disciplinary "science of man," and the predictions it generates for proximate-level determinants of social behavior, add significantly to our understanding of and potential for managing the people paradox, i.e., that the very things that bring us symbolic immortality often conflict with our prospects for survival. Analysis of immortality projects as one of the proximate barriers to addressing climate change is both cautionary and hopeful, providing insights that should be included in the cross-disciplinary quest to uncover new pathways toward rational, social change.
\end{abstract}

Key Words: environmental behavior, birds, icons, social psychology, terror management theory, conservation; immortality projects

\section{INTRODUCTION}

Reversing the trajectory of global climate change requires widespread support for policies and incentives that will reduce carbon emissions. Although it is certainly in the world's best interest to promote carbon neutrality, it is not in the material interests of nations or individuals to hinder economic growth (Dyson 2006, Woodward 2008). Given that the link between the use of fossil fuel and economic development is a significant politicaleconomic barrier to restraint, the greatest hope for transformative change may be mobilization of ideological communities toward a ground swell of support for carbon neutrality.

The popularity of environmental education initiatives, including Al Gore's The Climate Project, attests to a belief that increasing awareness helps change individual behavior and promotes advocacy, but there is little real evidence that this is so (Blumstein and Saylan 2008). Although short-term behaviors often shift as a consequence of educational experiences (Kaiser and Fuhrer 2003), the resulting behavioral changes are typically short lived (Dwyer et al. 1993). We must question the assumption that increased knowledge of the dangers will generate a sustained rational response (Janssen and de Vries 1998, Dessai et al. 2004), because even the behavior of conservation biologists, who frequently drive large pickup trucks and four-wheeldrive vehicles, suggests that this is not the case. Behavioral response to the threat of global climate change simply does not match its unique potential for cumulative, adverse, and potentially chaotic outcomes (Dyson 2006). 
Despite ample evidence of an inevitable rise in atmospheric carbon dioxide during this century, Dyson (2006:120) argues that "humanity's experience of another difficult 'long' threat-HIV/ AIDS - reveals a broadly analogous sequence of human reactions. In short, (i) scientific understanding advances rapidly, but (ii) avoidance, denial, and recrimination characterize the overall societal response, therefore (iii) there is relatively little behavioral change, until (iv) evidence of damage becomes plain." The implication is that only direct experience with adverse outcomes leads to behavioral change, leaving us with the question of why the connection is so flimsy between what we know, what we value, and how we behave.

This question is rooted in the ideas of Ernest Becker, whose work culminated in two companion syntheses: The Denial of Death (1973) and Escape from Evil (1975). Here I expand Becker's cultural and proximate psychological understanding of human behavior to provide new insights into the challenge of implementing a rational response to global climate change. First, I summarize Becker's ideas on psychological repression of death anxiety through symbolic perpetuation of the self, and clarify the empirical framing of these ideas within the branch of social psychology known as "terror management theory" (TMT). I then use TMT research paradigms, which examine how thinking about death influences human behavior (Pyszczynski et al. 2006), to make predictions about how individuals and groups respond to mortal environmental problems like global climate change. The purpose of this synthesis is to explore one of the key psychological links between the reality of global climate change and the difficulty of mobilizing individuals and groups to confront the problem in a rational and timely manner. I focus on Becker's mechanistic (proximate) understanding of self-esteem striving, transference idealization, world view defense, and outgroup antagonism, illuminating several ways in which death-denying defenses and perpetuation of the symbolic self are psychological barriers to the development of modern, rational, sustainable belief systems, advocacy, and action.

\section{ERNEST BECKER'S IDEAS ON DENIAL OF DEATH AND THE SYMBOLIC SELF}

Becker's ideas have their historical roots in psychoanalysis (Rank 1941, Freud 1957, Brown
1985), his own disciplinary training in cultural anthropology (Hocart 1933, 1952, 1954, Becker 1971b) and sociology (Berger and Luckmann 1966, Becker 1971b), as well as in the philosophical pragmatism of John Dewey (Dewey and Bentley 1949). In The Denial of Death (1973), he proposed that human beings are predisposed to suppress thoughts of death to manage anxiety about the inevitability of mortality. Along with an enlarged brain and prefrontal cortex, human beings gained the capacity to use symbolic language and simulate experience, imagining the future before it happens (Rakic 1995, Leifer 1997). One component of consciousness is awareness of a "self" (Dennett 2004), and with this awareness comes awareness of the inevitability of mortality. Becker invoked Rank's (1941) assertion that fear of annihilation is the primary source of human anxiety. The flip side of fear of annihilation is anxiety about the self, which is the basis of neurosis.

Becker suggested that thinking about death is so costly that denial of death is ubiquitous and explains the majority of human mythologies and world views. He proposed that we repress thoughts of death and dying by pushing them out of consciousness and creating a mythical, culturally and socially informed reality that provides a context for self-esteem or even heroism. We use our unique self-awareness and imagination to create a fictional self through shared meaning, myths, cultural world views, and projects for building self-esteem (causa sui or Oedipal projects). Cultural world views include all ways of viewing the world, from belief in the supernatural to the creation of meaning within cultures of honor, materialism, myths, nationalism, religion, and reverence for youthfulness, beauty, or artistry. Ancestral cultures were more integrated and provided a consistent context for self-esteem with well-defined roles that governed interactions within ritual units or social groups, but, in the modern world, in which people no longer operate within a single culture, we have a larger variety of contexts or world views within which to strive for self-esteem as doctors and scientists, soldiers and nationals, parishioners and priests, consumers and aesthetes, artists and athletes, cult or gang members, and world leaders (Becker 1973, Lifton 1993).

Another way to reduce anxiety about mortality is to project power and importance onto some idealized other, often a celestial god. In Becker's (1973) words, we are "meaning seeking creatures." We have the capacity to see ourselves in relation to 
larger systems, including the cosmos, and to comprehend the idea that we are small and insignificant relative to what we see in the sky: the stars, the planets, the universe (Leifer 1997). Because this is terrifying (Rank 1932), we repress thoughts of death and project a power and importance onto something larger that will save us. This psychological phenomenon, known as transference, was proposed by Freud (1957) to describe patients' projection of aspects of the parent-child power and love relationship onto the analyst. Recently, controlled behavioral experiments provide empirical support for transference idealization with anxiety-reducing effects that can be understood using neural network approaches (Gabbard 2006) and visualized with neural imaging techniques (Gerber and Peterson 2006). Charismatic leaders and deities are common soteriological transference objects, but so are movie stars, political leaders, lovers, and teachers. The exact nature of transference varies, but what is critical is that transference objects appear larger than life and more enduring than the mortal self.

The proximate psychological mechanisms that form the basis of the ideas presented here neither conflict with nor support hypotheses at the ultimate, evolutionary level of analysis, at which the experience of and defenses against existential terror can be viewed either as costly byproducts of the evolution of consciousness (Landau et al. 2006) or, more plausibly, as products of selection resulting from the advantages of ideologically based withingroup cooperation and extra-group competition (Hardin 1968, Hauert et al. 2002, 2006, Wilson 2006). This treatment focuses only on the proximate level of analysis while recognizing that hypotheses at the two levels are not mutually exclusive and thus do not compete (Reeve and Sherman 1993).

Becker connected the denial of death to a broad suite of behaviors enacted in defense of a cultural world view, placing his ideas within the context of Western society's increasingly distant relationship to nature and rejection of death as an integral part of life (Becker 1975, Lifton 1979). His goal was to revitalize the enlightenment tradition (Anchor 1979) and develop a "science of man" that would discover the psychological reasons why people gravitate toward finding meaning within some context of cosmic significance, why group ideologies so often involve literal or symbolic immortality, why cultural ideologies are so often the grounds upon which battle lines are drawn, and why so much of human motivation is subconscious and thus outside awareness.

Applying these ideas to the environment, I propose that unconscious defenses identified by TMT can both block and promote rational responses to global climate change. Given the paradox that most modern immortality-striving hero systems hinder our chances of survival, what might we learn by investigating the psychological mechanisms governing our choices? Understanding proximate behavioral mechanisms, particularly unconscious motivations that govern decision making, may reveal methods for generating a sustained response to global climate change in the short term and provide insights that individuals and institutions can use to foster rational responses to escalating environmental crises over the long term.

\section{TERROR MANAGEMENT THEORY AND EMPIRICAL EVIDENCE FOR DENIAL OF DEATH AS AN IMPORTANT FACTOR IN HUMAN BEHAVIOR}

Terror management theory (TMT) is the formalization of Becker's ideas within the field of social psychology. Although not universally accepted (Navarrete and Fessler 2005), TMT is supported by evidence from more than 300 empirical studies testing a wide range of predictions with Western and indigenous societies in various parts of the globe (Pyszczynski et al. 2006). For this reason alone, it is worth taking seriously and integrating with environmental thinking, particularly with regard to human responses to climate change.

Pyszczynski et al. (1999) proposed a dual-process model in which both proximal and distal terror management defenses comprise the anxietybuffering system required to keep death thoughts at bay. Proximal defenses are launched when death thoughts rise to consciousness, whereas distal defenses are responsible for keeping death thoughts unconscious. The experiments ask whether TMT is a good predictor of how people will behave in response to "death primes," which are stimuli that increase mortality salience, rendering unconscious thoughts of death conscious or, if they remain unconscious, making death thoughts more accessible. 


\section{PROXIMAL DEFENSES AND PREDICTED RESPONSES TO INFORMATION ABOUT GLOBAL CLIMATE CHANGE}

Proximal defenses use rational thinking and deploy immediately after conscious thoughts of death are triggered; they involve both active suppression and cognitive distortions that relegate the problem of death to the distant future (Pyszczynski et al. 1999). Distraction, planning, and biased cognition, such as denial of risk and rationalization, all serve to suppress thoughts of death, reducing abstract awareness of mortality. Individuals filter information in ways that appear rational, biasing cognition away from the inevitability of death. To this end, people are prone to deny the validity of research and tests indicating that their lives could be in danger (Kunda 1987) and elect to endure pain and suffering so long as it is accompanied by a promise of long life (Quattrone and Tversky 1984).

Where global climate change is concerned, proximal defenses to thinking about mortality are likely to manifest in three ways: (1) denial of climate change, i.e., climate skeptics; (2) denial that humans are the cause of climate change; and (3) a tendency to minimize or project the impacts of climate change far into the future, where they no longer represent a personal danger (Table 1). For example, after viewing the apocalyptic film "The Day After Tomorrow," subjects' beliefs in the likelihood of extreme events declined (Lowe et al. 2006). Although this result was neither studied nor interpreted within the context of TMT, it is consistent with proximal defenses. Proximal defenses cause people to minimize the severity of mortal problems. If thinking about climate change triggers proximal defenses, people who say that they believe climate change is occurring will still tend to underestimate the need for an immediate response. As conditions worsen and it becomes increasingly difficult to deny the effects of global climate change, more people will probably switch over to distal defenses.

\section{HOW DISTAL DEFENCES INFLUENCE HUMAN CAPACITY TO RESPOND TO GLOBAL CLIMATE CHANGE}

Distal terror management defenses comprise the most interesting predictions of Becker's work. They are thought to be activated when the accessibility of death thoughts increases, although these thoughts still remain unconscious (Pyszczynski et al. 1999). Distal defenses are symbolic and occur in the absence of negative affect, physiological arousal, or distress; they are deployed in response to verbal or written death primes and subliminal death stimuli, which strongly supports the idea that they are unconsciously motivated. Experiments indicate that bolstering self-esteem helps to keep death thoughts at bay (Greenberg et al. 1992b). Consequently, threats to self-esteem can elicit terror management defenses, whereas factors such as a history of secure attachment or thinking about one's own secure relationship have buffering effects (Florian and Mikulincer 1998, Mikulincer and Florian 2000, Mikulincer et al. 2003). Experiments designed to explore distal defenses are intriguing because they tap into unconscious motivation in compelling ways, asking whether interventions (primes) that increase mortality salience also increase the individual's striving for self-esteem, defense of his or her own world view, antagonism toward outgroups, and idealization of lovers and leaders.

Distal defenses are also counterintuitive. If primes related to global climate change increase the accessibility of death thoughts, exposure should lead to (1) transference idealization in the form of blind following and a reduction in the rational criticism of public figures, particularly charismatic leaders; (2) increased striving for self-esteem, which in Western society could mean counterintuitive increases in status-driven consumerism, materialism, and other behaviors that increase carbon emissions; (3) increased outgroup antagonism, not just between environmentalists and anti-environmentalists, but among religious groups, gangs, and other ideological groups; and (4) a tendency to bolster the existing world view even if it is not sustainable. A startling example of this is the "Drill, baby, drill" chant that erupted at the Republican National Convention in Minneapolis, Minnesota, USA, in 2008. No rational approach could ever produce this gleeful negation of drilling's profound aesthetic and environmental costs.

In past studies, death primes have included questions that cause subjects to imagine their own deaths, graphic footage of the deaths of others, indirect triggers including proximity to a funeral home, and subliminal messages like flashing the word "death" imperceptibly across a computer screen (Solomon et al. 2004). Controls involve anxiety-producing stimuli like physical pain, e.g., 
Table 1. Terror management theory predictions for how thinking about mortality in association with climate change (GCC) affects people's behavior. GCC primes include a range of stimuli that cause people to think about the impacts of and risks associated with global climate change.

\begin{tabular}{ll}
\hline \hline Hypothesis & Predictions \\
\hline GCC primes increase death thought accessibility. & $\begin{array}{l}\text { Death thought accessibility will increase when people are } \\
\text { asked to think about global climate change. High-severity } \\
\text { forecasts will increase death thought accessibility more than } \\
\text { low-severity forecasts. }\end{array}$
\end{tabular}

People will exhibit proximal defenses in response to information about GCC by:

Denying that the threat exists;

Accepting GCC, but denying that humans are the cause;

Accepting GCC, but pushing the timing far into the future.

People will exhibit distal defenses in response to information about GCC by:

Striving for self-esteem;

Defending their world views;

Showing antagonism toward outgroups;

Transference idealization.
GCC prime increases both the frequency and intensity of climate change denial.

GCC prime increases the intensity of denial that humans cause climate change.

GCC prime increases estimates of the amount of time until the occurrence of severe climate-change effects or the tipping point.

GCC prime increases striving for self-esteem within the context of the individual's world view.

GCC prime increases the intensity and frequency of the world view defense, e.g., making donations to a political party, espousing a world view, defending a world view.

GCC prime increases the devaluation and marginalization of and aggression and violence against individuals and groups with opposing world views.

GCC prime increases the valuation of leaders with a shared world view and the propensity to grant power to world view leaders. dental pain; psychologically stressful situations unrelated to death, e.g., having to give a speech or take an exam; and subliminal presentations of a neutral word that has the same length and number of vowels as the word "death" (Arndt et al. 1997, Solomon et al. 2004). I know of no study that investigated whether delivering information on global climate change increases death thought accessibility. However, if it does, then experiments that manipulate the way in which information on global climate change is presented, including the extent to which graphic details or the potential for human mortality are revealed, could prove useful not only for testing the idea that mortality salience influences human response to global climate change but also for determining the most effective ways to structure climate change education.

A critical but frequently misunderstood component of TMT is that distal defenses are designed to reinforce a "symbolic self." This means that TMT does not predict that individuals will choose the strategy most likely to avoid death or harm. If it were that simple, making death thoughts more accessible would cause people to drive more carefully. However, when driving and self-esteem 
are linked, Becker's hypothesis makes the opposite prediction, and this was borne out in an experiment in which subjects who linked driving with selfesteem drove faster and became more reckless in response to stimuli that made them think about death, sacrificing true safety for false safety in the form of defense of the ego (Ben-Ari et al. 1999).

This result parallels the prediction that increased confrontation with the problem of global climate change will lead to increased consumerism and status-seeking through material wealth (Kasser and Sheldon 2000). This is the crux of Becker's argument: The behaviors people exhibit are not necessarily those that reduce the risk of death, and in fact they may sometimes increase it as long as they also bolster the individual's symbolic self and the complex, immortality-striving hero system that defines it. Such counterintuitive responses can be seen in some of the studies integrated into the discussion of climate change below, and are but a small sample of a large inventory of experimental studies supporting the use of distal defenses in the management of existential terror.

\section{WHEN CLIMATE CHANGE PRIMES ELICIT TERROR MANAGEMENT DEFENSES}

What happens when discussion of climate change makes it difficult for people to repress thoughts of death? We have seen that death-denying defenses are often counterintuitive, causing individuals to incur greater rather than less danger and leading to irrational outcomes and behavior. If confronting global climate change increases mortality salience, which remains to be tested, the precise behavioral manifestations will likely be as varied as the many extant cultural world views. For example, people who find self-esteem via materialism and an ideology of entitlement will probably buy more SUVs and become more antagonistic toward environmental causes and points of view, favoring suppression of the environmental movement and harsher penalties for the more radical protestors. In contrast, people who find self-esteem through humanist ideologies or environmentalism should become increasingly militant and vocal about their causes. This clash between two major Western ideologies is likely to produce even deeper ideological rifts within and outside the United States than we currently see.
Thinking about climate change may also result in ideological conflict within individuals. Environmental awareness and a tendency to promote conservation behavior will be undermined when the environmentalist ideology threatens an individual's self-esteem within some other ideological context. Because people adhere to more than one ideology (Lifton 1993), there is such a thing as a "materialistic environmentalist." This leads to the question of what is required for people to hold two conflicting ideologies at the same time; this question is understudied, and the outcome probably varies with personality type. Lifton (1993) discovered that "doubling," i.e., the creation of separate selves, occurred among doctors who became killers at Auschwitz; this is an extreme response that allows people to retain deeply discordant ideologies, which is difficult because internal conflict undermines self-esteem with guilt and shame.

How does TMT inform efforts to increase environmental awareness and behavior? First, it illustrates why Wilson's (2006) approach to the clergy, which explains how people can integrate concern for biodiversity within their existing world views, might be more productive than Dawkins's (2006) more direct approach, which contradicts and dismisses or even attacks the world view of much of humanity, arguing for an entirely new one. Second, it provides a mechanistic explanation for why the responses necessary to reduce carbon emissions may be difficult to come by even among conservationists. Finally, it identifies additional barriers to and possibilities for assembling ecological communities whose priorities match the real dangers we are facing, with the unifying characteristic being that the context for self-esteem and, most importantly, the doctrines of leaders are aligned with the mission of stopping climate change.

The integration of TMT with social theory may also prove useful in understanding the psychological impacts of the "risk society," which is less "progress-centric" and focuses instead on adaptation to the manufactured risks associated with human activity (Giddens 1990, Beck 1995). If the perception of risk, including the risks associated with climate change, increases death thought accessibility, and this becomes increasingly likely as the impacts of climate change reveal themselves, then efforts to move people toward environmentally responsible behaviors may have the opposite effect, causing them to purchase large gas-guzzling vehicles, listen to Rush Limbaugh, join 
fundamentalist cults, or, in the case of university faculty, hunker down and write more scientific papers.

We currently lack the basic understanding required to design educational structures to support leadership, resilience, and courageous responses to the problem of global climate change. Investigation of the psychological underpinnings of response to climate change is important in designing educational strategies, particularly those that involve teaching young people. I propose that inspiring young people to bring their talent, creativity, and energy to the table is insufficient without also providing a climate change ideology for the collective good. Social support and a reconfiguring of identity are critically important in overcoming addictions to nicotine and alcohol (Barber and Crisp 1995, Christakis and Fowler 2008), and the inability of environmental education projects to promote behavioral change may rest with their failure to provide a social context for selfesteem.

\section{NEW HISTORICAL SOURCES OF IMMORTALITY AND POWER AS PROXIMATE CAUSES OF ENVIRONMENTAL HARM}

Lifton (1993) proposed that, beginning in the 20th century, people were forced to adopt a many-sided ideology because of unprecedented change ranging from social and political dislocation to the expanding geography of employment opportunities. This dislocation, combined with the mass media revolution and the threat of human extinction, has required people to continuously recreate their symbols and become "fluid and many-sided." In ancestral societies, ideologies commonly focused on rebirth and renewal as forms of symbolic selfperpetuation. Becker (1975) wrote about the "new historical forms of immortality and power," the most universal and primary of which is money. Modern Western society has lost the alignment of community with the "ritual unit" or cultural world view (Becker 1973). Whereas the ritual unit was once the community or clan, today the ritual unit is often mismatched to the cultural grouping within which it resides. Although the family and the church or state continue to exist, the intermediate communities are either missing or transient, and not everyone has a defined role within which he or she can feel successful.
Because there are few cultures remaining that have not been superseded by larger entities, with tribes becoming townships, cities, states, and nations, we no longer have an "integrated world conception into which we fit ourselves with pure belief and trust" (Becker 1975). Although this might open up the possibility of a utopian, egalitarian, and secular society in which the combined gifts of individuals prevail, what we have in the West is a secular inequality devoid of a shared sense of the sacred and a heroism that triumphs over nature, perpetuating itself through new immortality ideologies that value material acquisitions and money. Lacking in heroism, these immortality ideologies come up empty or even inspire guilt. The irony of Western materialism is that wealth beyond the point of basic material comfort does not make people happy (Gilbert 2005).

Support for materialism as a functional immortality ideology comes from experimental evidence that thinking about death increases consumptive behavior (Kasser and Sheldon 2000). When subjects were asked to write essays about death and then project their circumstances 15 years down the line, they imagined themselves wealthier and with more possessions than did controls. More directly relevant to natural resource management, this pattern was upheld in a second experiment in which subjects in the "mortality salience" condition consumed resources more greedily in a forest management game than did control subjects. This suggests that mortality salience accelerates the tragedy of the commons (Hardin 1968). The impact of mortality salience on consumptive behavior can also be seen in response to television advertisements: With the increase in death-related news reports, it was possible to ask whether subjects exposed to news about death increased their valuations of high-status items for sale during television commercials. Subtle reminders of death caused viewers to place a higher value on highstatus items and to devalue low-status items (Mandel and Heine 1999). This effect was absent in control subjects who were not reminded of death. Given these results, increased mortality, e.g., from terrorism (Pyszczynski et al. 2002), war, and extreme weather, is likely to increase consumerism and carbon emissions.

Technocracy itself is an immortality ideology that, although it is coupled with materialism, has as part of its makeup an element of the magical and a belief that new tools and innovations provide solutions to 
both the small day-to-day problems of life and the larger problems of human happiness and mortality. Technology is entrancing, and, functionally, technologists become creators of magic and the wizards of today, claiming the same authority over technology that doctors claim over human health or shamans over the cursed. This has always been so, going back to ancestral peoples who learned to use fire, tools, wind, and wheels. Even in subsistence societies, technology has a greater impact on a variety of sociological variables than do supernatural or religious beliefs (Nolan and Lenski 1996).

Traditionally, technology consolidates power within a society and exacerbates inequity. What is interesting about the new information technologies is that they do both: They consolidate power with patents, exclusive intellectual capital, and expensive tools, and they distribute power through open source technologies and open communication networks. As such, they promote material segregation while at the same time providing a relatively open network within which ideological communities can function. Photo galleries, forums, listserves, Google groups, and new social networking tools like MySpace, Facebook, and Second Life present mechanisms for growing online communities. In this new virtual world, frequent interaction is easy to achieve, and the topics around which free choice interaction occurs can be very focused and specific, suggesting that large social networks function like smaller ideological communities once did in the real world. It is also true that, although the Internet can unite and assemble large communities of action, e.g., Moveon.org, it can also be used to manipulate. The complexity of its impact on culture, relationships, and environmental behavior is worthy of scrutiny and study.

Like materialism, technology offers opportunities for reducing the impacts of ideology and life-style on the environment, including the invention of tools that allow individuals to save energy (Midden et al. 2007) and social networks that encourage sustainable behaviors. The flip side of this is that technology and materialism both lead to the increased use of natural resources (Vlek and Steg 2007), and so both materialism and the belief in technological salvation in their present manifestations will ultimately have negative impacts on the conservation of natural resources and on our ability to reduce carbon emissions.

\section{CONSERVATION AS AN IMMORTALITY PROJECT: RECRUITING CONSERVATIONISTS FROM CULTURES OF HONOR}

Although cultures of honor likely have their evolutionary basis in mate competition (Shackelford 2005), when viewed through the psychological lens of Becker's ideas they provide a context for selfesteem. For example, urban gangs allow members to strive for self-esteem more successfully than within the broader cultural context of their urban schools or the monetary ideology of contemporary Western society (Lopez 1991). Cultures of honor form in response to marginalization, and their codes and ideologies are highly variable, although they all have self-esteem as a common ingredient. This is why disrespect or "dissing" figures so importantly as a context for conflict.

What is it about youth conservation corps projects that make them such a good fit for youth emerging from urban cultures of honor? The answer may be a simple one. Local, redemptive conservation projects focused on environmental justice communities have all of the trappings of an immortality project and provide a meaningful context within which imperiled youth can strive for self-esteem and happiness. Currently, youth conservation corps programs across the United States have more poor, inner city youth applying to join their ranks than they can accommodate. In many cases, the young men leave gangs and lucrative, but illegal, drug-dealing operations to dedicate themselves to the conservation corps, working for low pay and minimal scholarships. This trend may have direct parallels with the Civilian Conservation Corps enacted by Roosevelt as part of the New Deal in 1933. Members express the desire to better themselves and develop a sense of justice about issues of pollution and environmental degradation.

The link between self-esteem, the creation of communities of action, and justice issues is a powerful one that can be applied to climate change as well, because global climate change is predicted to have the greatest and earliest impacts on the poor. Becker's ideas translate into a hypothesis that has social value: What is lacking in many challenged communities is not merely resources, but the resilience that comes from having a supportive context for meaning. This thinking suggests that eco-groups can seed challenged coastal communities with the raw materials for participatory action 
research (Minkler 2000) toward improved resilience (Faber et al. 2001, Kuo 2001, Tidball and Krasny 2007); mental health (Faber et al. 2001); science, technology, engineering, and math learning; the management or remediation of environmental problems; and climate change activism.

Gangs are typically high in bonding social capital, with deep, close within-group connections, but low on bridging social capital, which involves connections among groups of different socioeconomic status and power (Bolin et al. 2004). If youth conservation projects provide a shared context for self-esteem and promote bonding social capital without providing opportunities for bridging social capital, they may simply create new "gangs." Providing opportunities for youth conservation corps to address issues with politicians and the broader community could create the bridging social capital required to avoid increases in outgroup antagonism.

\section{LEADERS, ARCHTYPES, AND TOTEMS: A PSYCHODYNAMIC THEORY OF SUSTAINABLE CULTURE}

In ancestral societies, nature was an integral part of immortality-striving rituals and symbolism, providing a context for the vital lies or "character armor" that people require to survive as conscious beings in a social world (Becker 1975). This integration is seen today in new religious environmental movements (Goodenough 1998, Ostrow and Rockefeller 2007), with both theistic and nontheistic emphasis on the spiritual dimensions of conservation (Goodenough 1998, Orr 2002). Although these movements may exacerbate ideological antagonism, they also hold promise for creating an ideological groundswell to reduce carbon emissions, particularly with the support of charismatic conservation leaders (see, for example, http://renewalproject.net ).

Nontheistic conservation communities often arise around ideological symbols or charismatic archtypes. The practice of bird watching in the United States has grown dramatically, increasing by $155 \%$ in the years from 1982 to 1995 (Fitzpatrick and Gill 2002). This rapid exponential growth, similar to the growth that sometimes accompanies new religious movements, suggests that bird conservation communities function as ideological entities. Concern for and ideal love of archetypal charismatic organisms such as birds can be interpreted within the context of transference idealization.

Like fantasy and belief in the supernatural, the idealization of birds may have anxiety-buffering effects (Solomon et al., in press). Belief in a supernatural higher power increases in response to reminders of death, regardless of whether that particular higher power is embodied by the subject's own belief system or that of an outgroup (Norenzayan and Hansen 2006). To the extent that birds elicit a religious fervor, ritual bird watching may serve an anxiety-buffering function that goes beyond the benefits of spending time outdoors; if this is so, then asking bird watchers to think about bird watching should reduce death thought accessibility and anxiety.

When it comes to climate change, birds may be superior archetypes to other charismatic organisms. Not quite celestial, they have the unusual capacity to take to the sky with a beauty, mystery, and charisma that renders them elusive, godlike, and apart from us. These characteristics make them ideal symbolic "transference objects" on which to project a striving for immortality. The connection between vitality and flight can be seen in ornithological literature of the early 20th century, when flowery, anthropomorphic language was not uncommon. Thomas Mason Earl wrote of a common nighthawk he observed over a 5-yr period, "But if she really ever noticed me giving her more than ordinary attention, she had never indicated that there was any reciprocal feeling of interest. No doubt she regarded all earth-walkers as worms of the dust, far inferior to her own kind that could mount like spirits to the vault of heaven" (Earl 1924). Studies indicate that people project more power onto objects that appear higher than lower in the visual field (Schubert 2005; Solomon et al., in press). In addition to altitude, flight itself appears to have special qualities; flight fantasies are universal across the spans of culture and time (Ogilvie 2004; Solomon et al., in press).

In a study of flight fantasy, participants primed with thoughts of death were more likely than controls to express the desire to fly. In another study by the same group of researchers, participants were asked to visualize a detailed flight fantasy, while "grounded participants" were asked only to visualize the rising sun. A previous study demonstrated that people asked to think about death 
gave George W. Bush elevated approval ratings (Landau et al. 2004). In the flight experiment, subjects who visualized themselves in flight were less likely than grounded participants to give Bush the high ratings typically associated with experimentally induced mortality salience; this indicates that flight visualization ameliorates terror management defenses (Landau et al. 2004; Solomon et al., in press). If birding has similar effects to thinking about flight, it may foster resilience to direct confrontation with the problem of climate change.

Among birds, iconic species may be particularly effective totems of immortality, providing support for understanding and addressing the problem of climate change. Just as the bald eagle is a symbol of national independence, strength, and freedom, it has become, for one inner city neighborhood, a symbol of community resilience. In the Earth Conservation Corps' experience of bringing back the bald eagle to Washington D.C. after a 50-yr absence, the eagles have become symbols of environmental justice and restoration for both the river and the community; each eaglet is an immortality symbol named after a young corps member murdered in the difficult neighborhood of Anacostia (Renard 2006). The eaglets are a symbolic perpetuation of these young lives and, as a consequence, solidify the ideology that holds the corps together.

The concept of birds as transference objects suggests several other ways in which birds have unexpected links with conservation behavior. First, the desire to save birds may be a pro-conservation terror management defense that elicits striving for self-esteem within the cultural world view of conservation activism. The idealization of birds as archetypal organisms may allow individuals to experience mortality threats associated with global climate change in a nonthreatening, non-selfreferent context and to practice with these threats much in the way that children are thought to practice with frightening thoughts through fantasy (Jones 2002). Becker (1967:126) described human beings as "the animal in nature who, par excellence, imposes symbolic categories of thought on raw experience."

Birds provide important connections with nature, even if the only contact is with non-native birds common in cities. Such contact may be the primary hope for mobilizing urban populations to care about environmental issues (Dunn et al. 2006). Currently, more than half the world's population lives in cities, and this constitutes a large segment of humanity that is disconnected from the natural world (Louv 2005). This realization is the underlying basis of programs like Celebrate Urban Birds at The Cornell Laboratory of Ornithology and the Council for Environmental Education's Flying Wild, which propose that teaching about birds close to home will re-establish these missing connections, reduce fear of nature, and get people to spend more unstructured time outdoors.

By merging two ideas, i.e., the personal connection to nature through birds (Dunn 2006) and the denial of death (Becker 1973), the growing attachment to and projection-idealization of birds and other charismatic species may provide an important route to helping the public to recognize, care about, and act upon climate change in a sustained way. It may be more effective than forecasting the impacts of climate change on human populations, because birds are external to self, and this appears to be an important characteristic of an immortality project. Birders may also prove more resilient to the stress associated with conservation work than their less bird-o-philic counterparts. These are testable ideas that may enhance the strategies of conservation organizations and improve the way in which we convey difficult and important information about global climate change.

Bird watching is not just a hobby, a labor of love, and a spiritual experience; it is also a culture of honor and a competitive sport with regional and national events like Big Day and Big Year. Birding conservation communities are stratified with status and leadership equivalent to birding prowess. They serve a social function worthy of study, and, as with any sport, bird watching provides a context for selfesteem. Interestingly, serious birding may have parallels with hunting, as opposed to gathering, because there appears to be a gender bias in which most of the top competitive bird watchers in the United States are male. Regardless, it is reasonable to hypothesize that bird watching communities provide the cultural context for the heroic enactments of competitive birders and the conservation efforts they support. 


\section{SCIENCE AS A PANACAEA: FETISHIZING THE PROBLEM OF GLOBAL CLIMATE CHANGE}

Academic science is both a world view and a context for self-esteem according to Becker (1975). This can lead scientists to imbue the scientific process with a power that it does not actually possess. Environmental biologists surely grasp the complexity of living systems and the requirement for data and accurate forecast modeling of the effects of global climate change. We also recognize how unpredictable the changes are given that global warming is likely to affect not just populations but community and ecosystem interactions. Studying global climate change is a way for scientists to feel that we are both conducting important research and contributing to the greater good, which bolsters selfesteem within two ideologies at once, namely, the ideology of science and the liberal political ideology that most environmental scientists ascribe to. Although research may provide major insights that help to mitigate change that is inevitable, terror management theory predicts that we will focus our attention and resources on discovery and mitigation for global climate change at the expense of actions that will stop the process from occurring in the first place. The frequency with which scientists currently discuss "adaptation to" and "mitigation for" climate change is disturbing, and may speak of a reluctance to confront the problem with a realistic attitude (Dyson 2006). Awareness of this possibility can help redirect scientists to circumvent distal defenses in this somewhat ironic context.

\section{THE BINARY NATURE OF PRESERVATION AS A CULTURAL WORLD VIEW: IS THERE POTENTIAL FOR A HEROIC SOCIETY?}

In his final book, Becker (1975) explored the potential for a heroic society. His analysis provided a new perspective on the psychodynamic basis of the tragedy of the commons (Hardin 1968). Now, $35 \mathrm{yr}$ after his death, how might we move forward toward understanding and addressing the problem of global climate change? Becker recognized that human beings are universal seekers of meaning who require opportunities for heroism and derive significance through their identification with the world views provided by relationships, religions, society, politics, and the arts (Becker 1971a). If true change requires both heroic leadership and a cultural context for the heroism of many, a cultural world view that incorporates both innovation and idealization of the natural world is the logical immortality project and the best opportunity for heroism in these times. Love of nature is a deep ethical and spiritual issue that is consistent with most belief systems. Preservation of land, species conservation, and the creation of innovative technologies to combat the problem of climate change provide profound opportunities for symbolic immortality.

When confronted authentically, without TMT defenses, the conservation ideology is mortality salient, beginning with the recognition that as individuals we will not go on and that continuation of the world with its rich complex of biodiversity is something we can no longer take for granted. What does it mean to preserve the wilderness and to be in the world with wildlife? What does it mean to be without it and to lose even one species? With consciousness comes a will to touch the world with our own special brand of humanness, i.e., our identity, and with this perhaps there is a vicarious sense of loss when another living species disappears. Whether it is the loss of the Hawaiian Po'o-uli (Melamprosops phaeosoma) or the apparent loss and resurrection of the Ivory-billed woodpecker (Campephilus principalis), we are elevated by the will of other creatures and diminished by their absence. This ideology, although psychospiritual in nature, promotes courage and encompasses a shared responsibility for other organisms and for tackling the problem of carbon emissions.

On the other hand, although transference idealization, an emphasis on charismatic species, and the promotion of conservation ideologies can foster sustainable behaviors by making use of what we know about distal terror management defenses, it is likely that mortality-salient philosophies and theologies hold the most promise for avoiding distal defenses and addressing the challenges of global climate change. Because increased mortality salience and outgroup antagonism are predicted outcomes of rapid climate change, understanding how TMT defenses are influenced by rational analytic thinking becomes critically important.

Rational analytic thinking has a modulating effect on world view defense, reducing the impacts of mortality salience on behavior (Greenberg et al. 1992a). For example, priming with an argument for tolerance reduced the effects of mortality salience 
on outgroup antagonism in U.S. subjects confronted with individuals critical of the United States and its policies (Greenberg et al. 1994). If it is adopted with rational awareness, a cultural world view that values the natural world is authentic. However, because rational awareness is unstable, the practice of awareness requires repetition. In one experiment, individuals did not engage in symbolic world-view defense when they practiced a deep contemplation of death similar to Buddhist meditation (Greenberg et al. 1994). In general, deep contemplation and experiencing fear with conscious awareness helps individuals to avoid distal defenses, whereas feeling little or no fear is associated with an amplified, unconsciously motivated, world view defense, even in response to mild death stimuli (Greenberg et al. 1994). This body of research suggests that a combination of rational thinking and anxietyreduction techniques, such as meditation practice, will reduce reliance on distal defenses, leading to the direct confrontation with climate change required for authentic leadership.

Evidence of a universal moral grammar that places nonharming and fairness above community, authority, and purity (Haidt 2007) suggests a need to explore the ways in which moral axes interact with striving for self-esteem, world view defense, and social capital to shape cooperative and competitive behaviors and their impacts on responses to global climate change. Understanding individual variability in neurosis is also important, as suggested by the finding that physical sensitivity to sudden noise or reminders of danger is associated with a tendency to move toward a more conservative political stance (Oxley et al. 2008). The predictions of TMT, if integrated with resilience theory, might increase our understanding of the potential for social learning, visioning, scenario building, and leadership to support ideological and physical communities (Folke 2006).

TMT may prove useful in understanding the risk society (Beck 1991). Climate change has the quality of seeming both real and unreal, but, along with other current nuclear, chemical, and ecological risks, it demands that we move away from seeing the present in the light of progress relative to the past and instead view the present in the light of risks whose effects will be felt in the future (Beck 1991). This is a large and perhaps unprecedented shift for humankind, and our capacity to make this shift demands increased confrontation with mortality.
This means that understanding how risk interacts with our immortality-striving hero systems is fundamental to addressing the problems faced by a risk society. Contexts for self-esteem based upon progress are under threat; TMT predicts that this threat will create resistance and interfere with rational change. As Lifton (1993) suggested, undermining the symbol systems of "the immortalizing animal" can lead toward transformation and a sense of self that is based significantly on one's connection to mankind, or it can increase rigidity and bolster the desire to control circumstances. TMT predicts which experiences will tend to tip the balance away from rigid control in favor of connection.

Ulrich Beck (1991) suggested that a revival of the enlightenment, removed "from its professional incrustations,"will have to consider how people can change themselves, not only in trivial areas such as life conduct or peculiarities of personality, but also in such major things as their relationships to themselves, to the world, and to reality. It is not yet clear how many people have the capacity to engage in sustained restraint to avoid consequences, not for themselves, but for the future of their children and grandchildren. We are beginning to see the academic disciplines mobilize around the climate change issue. Recently, mainstream sociologists were called upon to overcome their disciplinary inhibitions against listening seriously to what scientists have to say about nature and the more recent inhibition against thinking about the future, and asked to engage fully with the issue of climate change (Leahy 2008, Lever-Tracy 2008). The climate change problem requires the attention of teams of natural and social scientists, including social psychologists, sociologists, ecologists, and other biogeochemical scientists, economists, anthropologists, and sociobiologists, all seeking to understand the people paradox and what it means for our potential for cooperation and our prospects for survival and quality of life in the future (HomerDixon 1991, Janssen and de Vries 1998, Killingback et al. 2006, Oxley et al. 2008). This attempt to bring into the discussion the work of Becker and the relevance of terror management theory is designed to begin one such dialog.

Making the unconscious conscious is both a cause of and a cure for distal defenses. Becker was aware of this conundrum and did not see his ideas as providing a panacea for the human condition, but as a starting point for understanding the key issues 
facing humanity. He saw people's relation to nature as one of six common human problems and lamented the shallowness of the modern connection to the natural world, contrasting it with the sacred view of natural objects common among indigenous people (Becker 1971a). Described as dark, his final work offered no solutions beyond a belief in the value and vitality of the spirit (Becker 1975). Nevertheless, Becker's ideas, along with the experimental work of others he influenced, bears the mark of a journey at the end of which is the recognition that answers to the large questions of life cannot be divorced from morality, ethics, responsibility, and even spirituality (Goodenough 1998, Orr 2002). In this he kept company with leading scientific and philosophical seekers of his time (Einstein 1950, White 1967).

The more clearly we can focus our attention on the wonders and realities of the universe about us, the less taste we shall have for destruction. (Carson 1962)

Responses to this article can be read online at: http://www.ecologyandsociety.org/voll4/iss 1/art34/ responses/

\section{Acknowledgments:}

I thank the late Ernest Becker for the enduring gifts of wisdom and insight that were his legacy and the TMT researchers for bringing his ideas into the empirical realm, where they can be "heard" by positivist scientists. This synthesis is no substitute for reading Becker's original work, which I highly recommend. I have conversed in person and via email with scholars from a diversity of fields at Cornell and beyond, including Marie Becker-Pos, Barbara Bedford, Chuck Geisler, Neil Elgee at the Ernest Becker Foundation, Steve and Natalia Emlen, Karim Aly-Kassam, Walt Koenig, Ron Leifer, David Orr, Sheldon Solomon, Rich Steadman, and David Sloan Wilson. Each person I spoke with changed my thinking in meaningful ways. I am indebted to Sheldon Solomon, Tom Pyszczynski, Jeff Greenberg, and Mark Landau for sharing unpublished manuscripts and to Sheldon, two anonymous reviewers, the associate editor, and the editor, Carl Folke, for reading earlier versions of this manuscript. Finally, Ron Leifer, a goodfriend and close colleague of Ernest Becker in the 1960s, provided critical insights and encouragement throughout my foray into this new area of scholarship, literally helping me to refine my thinking every step of the way. To the extent that I have interpreted Becker correctly, it is in large part due to discussions, both challenging and supportive, with him.

\section{LITERATURE CITED}

Anchor, R. 1979. The enlightenment tradition. University of California Press, Berkeley, California, USA.

Arndt, J., J. Greenberg, T. Pyszczynski, and S. Solomon. 1997. Subliminal presentation of death reminders leads to increased defense of the cultural worldview. Psychological Science 8:379-385.

Barber, J., and B. Crisp. 1995. Social support and prevention of relapse following treatment for alcohol abuse. Research on Social Work Practice 5:283-296.

Beck, U. 1991. Ecological enlightenment: essays on the politics of the risk society. Humanites Press, Atlantic Highlands, New Jersey, USA.

Beck, U. 1995. Ecological politics in an age of risk. Polity Press, Cambridge, UK.

Becker, E. 1971a. The birth and death of meaning. Free Press, New York, New York, USA.

Becker, E. 1971b. The lost science of man. Braziller, New York, New York, USA.

Becker, E. 1973. The denial of death. Free Press, New York, New York, USA.

Becker, E. 1975. Escape from evil. Free Press, New York, New York, USA.

Ben-Ari, O. T., V. Florian, and M. Mikulincer. 1999. The impact of mortality salience on reckless driving: a test of terror management mechanisms. Journal of Personality and Social Psychology 76:35-45.

Berger, P., and T. Luckmann. 1966. The social construction of reality: a treatise in the sociology of knowledge. Doubleday, New York, New York, USA. 
Blumstein, D., and C. Saylan. 2008. The failure of environmental education (and how to fix it). PLoS Biology 5(5): e120 doi:10.1371/journal.pbio.0050120.

Bolin, B., E. Hackett, S. Harlan, A. Kirby, L. Larsen, A. Nelson, T. Rex, and S. Wolf. 2004. Bonding and bridging: understanding the relationship between social capital and civic action. Journal of Planning Education and Research 24:64-77.

Brown, N. O. 1985. Life against death: the psychoanalytic meaning of history. Weslyan University Press, Middletown, Connecticut, USA.

Carson, R. 1962. Silent spring. Houghton Mifflin, Boston, Massachusetts, USA.

Christakis, N., and J. Fowler. 2008. The collective dynamics of smoking in a large social network. New England Journal of Medicine (358):2249-2258.

Dawkins, R. 2006. The God delusion. Houghton Mifflin, Boston, Massachusetts, USA.

Dennett, D. C. 2004. Freedom evolves. Penguin Books, London, UK.

Dessai, S., W. Adger, M. Hulme, J. Turnpenny, J. Kohler, and R. Warren. 2004. Defining and experiencing dangerous climate change: an editorial essay. Climatic Change 64:11-25.

Dewey, J., and A. Bentley. 1949. Knowing and the known. Beacon Press, Boston, Massachusetts, USA.

Dunn, R. R., M. C. Gavin, M. C. Sanchez, and J. N. Solomon. 2006. The pigeon paradox: dependence of global conservation on urban nature. Conservation Biology 6:1814-1816.

Dwyer, W., F. Leeming, M. Cobern, B. Porter, and J. Jackson. 1993. Critical review of behavioral intervention to preserve the environment. Environment and Behavior 25:274-321.

Dyson, T. 2006. On development, demography and climate change: the end of the world as we know it? Population and Environment 27:117-149.

Earl, T. 1924. A nighthawk's roosting place. Wilson Bulletin 36:185-188.
Einstein, A. 1950. Out of my later years. Philosophical Library, New York, New York, USA.

Faber, T., F. Kuo, and W. Sullivan. 2001. Coping with ADD: the surprising connection to green play settings. Environment and Behavior 33:54-77.

Fitzpatrick, J. W., and F. B. Gill. 2002. Birdsource: using birds, citizen science, and the Internet as tools for global monitoring. Pages 165-185 in J. N. Levitt, editor. Conservation in the Internet Age: threats and opportunities. Island Press, Washington, D.C., USA.

Florian, V., and M. Mikulincer. 1998. Symbolic immortality and the management of the terror of death: the moderating role of attachment style. Journal of Personality and Social Psychology 74:725-734.

Folke, C. 2006. Resilience: the emergence of a perspective for social-ecological systems analysis. Global Environmental Change 16:253-267.

Freud, S. 1957. Five lectures on psycho-analysis. Hogarth Press, London, UK.

Gabbard, G. 2006. A neuroscience perspective on transference. Pages 189-196 in: Proceedings of the 6th Delphi International Psychoanalytic Symposium. (Delphi 2006). Elsevier, Amsterdam, The Netherlands.

Gerber, A., and B. Peterson. 2006. Measuring transference phenomena with fMRI. Journal of the American Psychoanalytic Association 54:1319-1325.

Giddens, A. 1990. The consequences of modernity. Stanford University Press, Stanford, California, USA.

Gilbert, D. 2005. Stumbling on happiness. Vintage Books, New York, New York, USA.

Goodenough, U. 1998. The sacred depths of nature. Oxford University Press, Oxford, UK.

Greenberg, J., T. Pyszczynski, S. Solomon, L. Simon, and M. Breus. 1994. Role of consciousness and accessibility of death-related thoughts in mortality salience effects. Journal of Personality and Social Psychology 67:627-637. 
Greenberg, J., L. Simon, T. Pyszczynski, S. Solomon, and D. Chatel. 1992a. Terror management and tolerance: Does mortality salience always intensify negative reactions to others who threaten one's worldview? Journal of Personality and Social Psychology 63:212-220.

Greenberg, J., S. Solomon, T. Pyszczynski, A. Rosenblatt, J. Burling, D. Lyon, and L. Simon. $1992 b$. Assessing the terror management analysis of self-esteem: converging evidence of an anxiety buffering function. Journal of Personality and Social Psychology 63:913-922.

Haidt, J. 2007. The new synthesis in moral psychology. Science 316:998-1002.

Hardin, G. 1968. The tragedy of the Commons. Science 162: 1243-1248.

Hauert, C., S. De Monte, J. Hofbauer, and K. Sigmund. 2002. Volunteering as Red Queen mechanism for cooperation in public goods games. Science 296:1129-1131.

Hauert, C., M. Holmes, and M. Doebeli. 2006. Evolutionary games and population dynamics: maintenance of cooperation in public goods games. Proceedings of the Royal Society of London B 273:2565-2570.

Hocart, A. 1933. The progress of man. Oxford University Press, London, UK.

Hocart, A. 1952. The life-giving myth. Methuen, London, UK.

Hocart, A. 1954. Social origins. Watts, London, UK.

Homer-Dixon, T. 1991. On the threshold: environmental changes as causes of conflict. International Security 16(2):76-116.

Janssen, M., and B. de Vries. 1998. The battle of perspectives: a multi-agent model with adaptive responses to climate change. Ecological Economics 26:43-65.

Jones, G. 2002. Killing monsters: why children need fantasy, super heroes, and make-believe violence. Basic Books, New York, New York, USA.
Kaiser, F., and U. Fuhrer. 2003. Ecological behavior's dependency on different forms of knowledge. Applied Psychology: an International Review 52:598-613.

Kasser, T., and K. M. Sheldon. 2000. Of wealth and death: materialism, mortality salience, and consumption behavior. Psychological Science 11:348-351.

Killingback, T., J. Bieri, and T. Flatt. 2006. Evolution in group-structured populations can resolve the tragedy of the Commons. Proceedings of the Royal Society of London B 273:1477-1482.

Kunda, Z. 1987. Motivated inference: self-serving generation and evaluation of causal theories. Journal of Personality and Social Psychology 53:636-647.

Kuo, F. 2001. Coping with poverty: impacts of environment and attention in the inner city. Environment and Behavior 33:5-34.

Landau, M., S. Solomon, J. Greenberg, F. Cohen, T. Pyszczynski, J. Arndt, C. Miller, D. Ogilvie, and A. Cook. 2004. Deliver us from evil: the effect of mortality salience and reminders of 911 on support for President George W. Bush. Personality and Social Psychology Bulletin 30:1135-1150.

Landau, M., S. Solomon, T. Pyszczynski, and J. Greenberg. 2006. On the compatibility of terror management theory and perspectives on human evolution. Evolutionary Psychology 5:476-519.

Leahy, T. 2008. Discussion of "Global warming and sociology." Current Sociology 56:475-484.

Leifer, R. A. 1997. The Happiness Project: transforming the three poisons that cause the suffering we inflict on ourselves and others. Snow Lion Press, Ithaca, New York, USA.

Lever-Tracy, C. 2008. Global warming and sociology. Current Sociology 56:445-466.

Lifton, R. 1979. The broken connection. Basic Books, New York, New York, USA.

Lifton, R. 1993. The Protean self: human resilience in an age offragmentation. Basic Books, New York, New York, USA. 
Lopez, J. M. 1991. Profiles in vengeance: the quest for a chicano gang worldview. Mexican Studies 7:319-329.

Louv, R. 2005. Last child in the woods: saving our children from nature deficit disorder. Algonquin Books, Chapel Hill, North Carolina, USA.

Lowe, T., K. Brown, S. Dessai, M. de Franca Doria, K. Haynes, and K. Vincent. 2006. Does tomorrow ever come? Disaster narrative and public perceptions of climate change. Public Understanding of Science 15:435-457.

Mandel, N., and S. J. Heine. 1999. Terror management and marketing: He who dies with the most toys wins. Association for Consumer Research Proceedings 26:527-532.

Midden, C., F. Kaiser, and L. McCalley. 2007. Technology's four roles in understanding individuals' conservation of natural resources. Journal of Social Issues 63:155-174.

Mikulincer, M., and V. Florian. 2000. Exploring individual differences in reactions to mortality salience: Does attachment style regulate terror management mechanisms? Journal of Personality and Social Psychology 79:260-273.

Mikulincer, M., V. Florian, and G. Hirschberger. 2003. The existential function of close relationships: introducing death into the science of love. Personality and Social Psychology Review 7:20-40.

Minkler, M. 2000. Using participatory action research to build healthy communities. Public Health Reports 115:191-197.

Navarrete, C. D., and D. M. T. Fessler. 2005. Normative bias and adaptive challenges: a relational approach to coalitional psychology and a critique of terror management theory. Journal of Evolutionary Psychology 3:297-325.

Nolan, P., and G. Lenski. 1996. Technology, ideology, and societal development. Sociological Perspectives 39:23-38.

Norenzayan, A., and I. Hansen. 2006. Belief in supernatural agents in the face of death. Personality and Social Psychology Bulletin 32:174-187.
Ogilvie, D. 2004. Fantasies of flight. Oxford University Press, Oxford, UK.

Orr, D. 2002. Four challenges of sustainability. Conservation Biology 16:1457-1460.

Ostrow, M., and T. Rockefeller. 2007. Renewal. The Renewal Project, Walnut Creek, California, USA.

Oxley, D., K. Smith, J. Alford, M. Hibbing, J. MIller, M. Scalora, P. Hatemi, and J. Hibbing. 2008. Political attitudes vary with physiological traits. Science 321:1667-1670.

Pyszczynski, T., J. Greenberg, and S. Solomon. 1999. A dual-process model of defense against conscious and unconscious death-related thoughts: an extension of terror management theory. Psychological Review 106:835-845.

Pyszczynski, T., J. Greenberg, S. Solomon, and M. Maxfield. 2006. On the unique psychological import of the human awareness of mortality: theme and variations. Psychological Inquiry 17:328-356.

Pyszczynski, T., S. Solomon, and J. Greenberg. 2002. In the wake of 9/11: the psychology of terror. American Psychological Association, Washington, D.C., USA.

Quattrone, G. A., and A. Tversky. 1984. Causal versus diagnostic contingencies: on self-deception and on the voter's illusion. Journal of Personality and Social Psychology 46:237-248.

Rakic, P. 1995. A small step for the cell, a giant leap for mankind: a hypothesis of neocortical expansion during evolution. Trends in Neuroscience 18:383-388.

Rank, O. 1932. Art and artist: creative urge and personality development. Knopf, New York, New York, USA.

Rank, O. 1941. Beyond psychology. Dover Books, New York, New York, USA.

Reeve, H. K., and P. W. Sherman. 1993. Adaptation and the goals of evolutionary research. Quarterly Review of Biology 68:1-32.

Renard, R. 2006. The river of hope. Earth Conservation Corps, Washington, D.C., USA. 
Schubert, T. 2005. Your highness: vertical positions as perceptual symbols of power. Journal of Personality and Social Psychology 89:1-21.

Shackelford, T. 2005. An evolutionary psychological perspective on cultures of honor. Evolutionary Psychology 3:381-391.

Solomon, J. N., J. Greenberg, and T. Pyszczynski. 2004. The cultural animal: twenty years of terror management theory and research. Pages 13-34 in J. Greenberg, A. E. Koole and T. Pyszczynski, editors. Handbook of experimental existential psychology. Guilford Press, New York, New York, USA.

Solomon, S., J. Greenberg, T. Pyszczynski, F. Cohen, and D. Ogilvie. In press. Teach these souls to fly: supernatural as human adaptation. In $\mathrm{M}$. Schaller, A. Norenzayan, S. Heine, T. Yamagishi and T. Kameda, editors. Evolution, culture, and the human mind. Lawrence Erlbaum, Mahwah, New Jersey, USA.

Tidball, K., and M. Krasny. 2007. From risk to resilience: what role for community greening and civic ecology in cities? Pages 149-164 in A. Wals, editor. Social learning towards a more sustainable world. Wageningen Academic Press, Wageningen, The Netherlands.

Vlek, C., and L. Steg. 2007. Human behavior and environmental sustainability: problems, driving forces, and research topics. Journal of Social Issues 63:1-19.

White, L. 1967. The historical roots of our ecological crisis. Science 155:1203-1207.

Wilson, D. 2006. Human groups as adaptive units: toward a permanent consensus. Available online at: http://evolution.binghamton.edu/dswilson/resources/ publications resources/DSW02.pdf.

Woodward, D. 2008. Of "misguided" notions and misguiding nations: the growth report, poverty and climate change. Political Quarterly 79:618-627. 